\title{
Article
}

\section{Measurement of the Raman spectra and hygroscopicity of four pharmaceutical aerosols as they travel from pressurised metered dose inhalers (pMDI) to a model lung}

Davidson, N, Tong, H-J, Kalberer, M, Seville, Peter Craig, Ward, AD, Kuimova, MK and Pope, FD

Available at http://clok.uclan.ac.uk/16952/

Davidson, N, Tong, H-J, Kalberer, M, Seville, Peter Craig ORCID: 0000-00018546-3474, Ward, AD, Kuimova, MK and Pope, FD (2017) Measurement of the Raman spectra and hygroscopicity of four pharmaceutical aerosols as they travel from pressurised metered dose inhalers ( $p M D I)$ to a model lung. International Journal of Pharmaceutics, 520 (1-2). pp. 59-69. ISSN 0378-5173

It is advisable to refer to the publisher's version if you intend to cite from the work. http://dx.doi.org/10.1016/j.ijpharm.2017.01.051

For more information about UCLan's research in this area go to http://www.uclan.ac.uk/researchgroups/ and search for <name of research Group>.

For information about Research generally at UCLan please go to http://www.uclan.ac.uk/research/

All outputs in CLoK are protected by Intellectual Property Rights law, including Copyright law. Copyright, IPR and Moral Rights for the works on this site are retained by the individual authors and/or other copyright owners. Terms and conditions for use of this material are defined in the policies page. 


\section{Accepted Manuscript}

Title: Measurement of the Raman spectra and hygroscopicity of four pharmaceutical aerosols as they travel from pressurised metered dose inhalers (pMDI) to a model lung

Authors: N. Davidson, H.-J. Tong, M. Kalberer, P.C. Seville, A.D. Ward, M.K. Kuimova, F.D. Pope

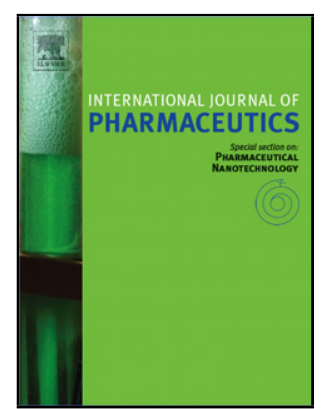

PII: S0378-5173(17)30060-1

DOI: http://dx.doi.org/doi:10.1016/j.ijpharm.2017.01.051

Reference: IJP 16383

To appear in: International Journal of Pharmaceutics

Received date: $\quad 24-10-2016$

Revised date: $\quad 12-1-2017$

Accepted date: $\quad$ 25-1-2017

Please cite this article as: Davidson, N., Tong, H.-J., Kalberer, M., Seville, P.C., Ward, A.D., Kuimova, M.K., Pope, F.D., Measurement of the Raman spectra and hygroscopicity of four pharmaceutical aerosols as they travel from pressurised metered dose inhalers (pMDI) to a model lung.International Journal of Pharmaceutics http://dx.doi.org/10.1016/j.ijpharm.2017.01.051

This is a PDF file of an unedited manuscript that has been accepted for publication. As a service to our customers we are providing this early version of the manuscript. The manuscript will undergo copyediting, typesetting, and review of the resulting proof before it is published in its final form. Please note that during the production process errors may be discovered which could affect the content, and all legal disclaimers that apply to the journal pertain. 


\section{Measurement of the Raman spectra and hygroscopicity of four pharmaceutical aerosols as they travel from pressurised metered dose inhalers (pMDI) to a model lung}

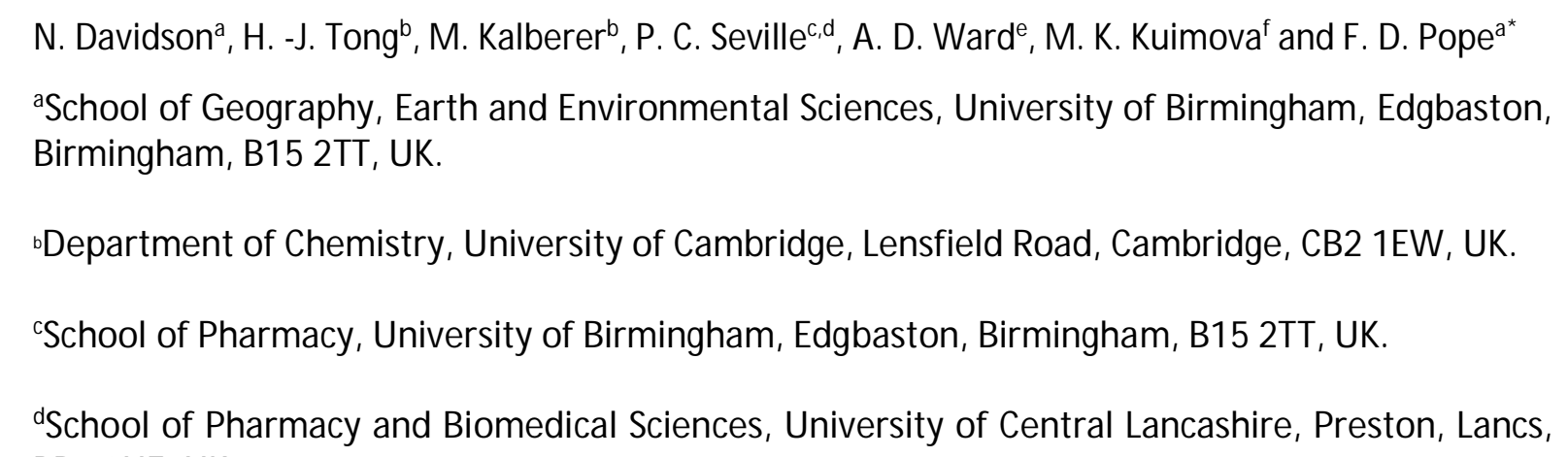




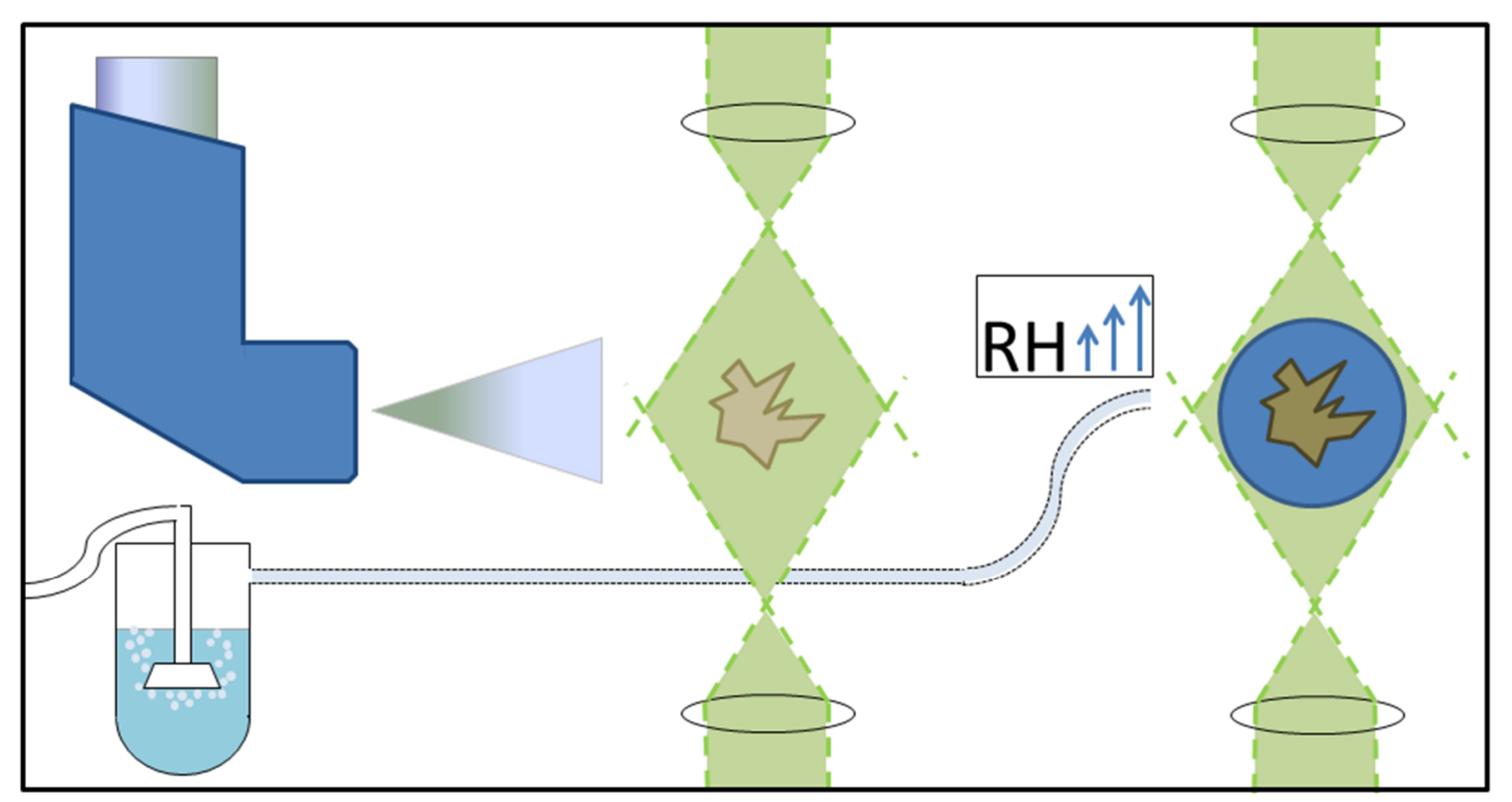

1 


\section{Abstract}

Particle inhalation is an effective and rapid delivery method for a variety of pharmaceuticals, particularly bronchodilation drugs used for treating asthma and COPD. Conditions of relative humidity and temperature inside the lungs are generally very different from the outside ambient air, with the lung typically being warmer and more humid. Changes in humidity, from inhaler to lung, can cause hygroscopic phase transitions and particle growth. Changing Increasing particle size and mass can negatively affect particle deposition within the lung leading to inefficient treatment, while deliquescence prior to impaction is liable to accelerate drug uptake. To better understand the hygroscopic properties of four pharmaceutical aerosol particles; pharmaceutical particles from four commercially available pressurised metered dose inhalers (pMDIs) were stably captured in an optical trap, and their composition was examined online via Raman spectroscopy. Micron-sized particles of salbutamol sulfate, salmeterol xinafoate, fluticasone propionate and ciclesonide were levitated and examined over a range of relative humidity values inside a chamber designed to mimic conditions within the respiratory tract. The effect of temperature upon hygroscopicity was also investigated for salbutamol sulfate particles. Salbutamol sulfate was found to have significant hygroscopicity, salmeterol xinafoate showed some hygroscopic interactions, whilst fluticasone propionate and ciclesonide revealed no observable hygroscopicity. Thermodynamic and structural modelling is used to explain the observed experimental results.

\section{Introduction}

\subsection{Respiratory drugs and drug delivery}

Respiratory ailments in the form of asthma and Chronic Obstructive Pulmonary Disease (COPD) are often managed with inhalable drugs. These drugs include beta-2 agonists such as salbutamol and salmeterol, and corticosteroids like fluticasone and ciclesonide.

Salbutamol sulfate and salmeterol xinafoate are both beta-2 andrenoceptor agonists, meaning they target the beta-2 receptors in bronchial muscle cells in a similar manner to adrenaline (Reisine, et al., 1983), forcing calcium out of the cells thus forcing them to relax, and opening the user's airways to allow easier breathing. Salbutamol (Ventalin ${ }^{\mathrm{TM}}$, Salamol ${ }^{\mathrm{TM}}$ ) has been a popular treatment for asthma and COPD since 1968 (Icha, 2007), while Salmeterol (Serevent ${ }^{\mathrm{TM}}$ ) was introduced in 1988 as a longer tastingalternative (UIIman \& Svedmyr, 1988).

Fluticasone propionate (Flixotide ${ }^{\mathrm{TM}}$ ) is an artificial corticosteroid that assists breathing by reducing inflammation in the lung lining (Harding, 1990)-Fluticasone propionate is also supplied as a combination inhaler with salmeterol xinafoate (Seretide ${ }^{\mathrm{TM}}$ ) due to their complementary modes of action (Woolcock, et al., 1996) (Chapman, et al., 1999) (Calverley, et al., 2003). Pure compounds rather than mixtures were investigated in this study.

Ciclesonide (Alvesco ${ }^{\mathrm{TM}}$ ) is a recently developed inhaled corticosteroid used as a treatment for asthma, hay fever and other respiratory ailments. In order to reduce the mouth and throat infections associated with respiratory steroid application, ciclesonide is designed to be biologically inactive until it interacts with esterase enzymes present in the lung (Mutch, et al., 2007) at which point it is 
hydrolysed to the active form desisobutyryl-ciclesonide; these enzymes are not found in the oral cavity to the same extent, and hence the potential benefit of reduced oropharyngeal side effects.

3 Inhalable drugs are predominately administered by nebuliser, dry powder inhaler (DPI) or by pressurised metered dose inhaler (pM DI). Powdered nebulisers have been in use since the $19^{\text {th }}$ century (Sanders, 2007), while cheaper and more portable pMDls were invented in 1955 (Purewal \& Grant, 1997). The $\mathrm{pM} D \mathrm{DI}$ is now the most popular device for delivering drugs to the human respiratory system in Great Britain and elsewhere (Lavorini, et al., 2011).

Modern pMDIs contain solid drug particles which are suspended in a liquefied hydrofluoroalkane propellant: most commonly HFA-134a (Cripps, et al., 2000) (Leach, 2005). Other co-solvents such as ethanol or oleic acid can be used depending on the drug (Bell \& Newman, 2007). The solvent rapidlyevaporates within a few milliseconds at ambient temperature upon activation of the pMDI (Stein, 2006), generating a fixed dose, inhalable aerosol of micron-sized solid drug particles travelling at a wide range of planar velocities into the user's trachaea and lungs (Crosland, et al., 2009).

\subsection{Significance of relative humidity and temperature on delivery efficiency}

Drugs acting within the respiratory tract are only effective if the particle aerodynamic diameters are in the $1-5 \mu \mathrm{m}$ range since larger particles cannot reach the receptor sites inside the lungs (Labiris \& Dolovich, 2003). Hygroscopic particles can change increase in size and mass as they collect water from the air (Broday \& Georgopoulos, 2001) which means that particles manufactured in the sizeappropriate range when dry may swell to larger than optimal size and higher than optimal mass by the time they pass through the moist air inside the trachea and into-towards the lungs. While larger particles are less likely to navigate to the regions where they can be absorbed most rapidly, more massive particles have greater momentum, are more likely to impact the back of the throat than pass into the lungs (Mansour, et al., 2016) and their direction of travel is less influenced by the Brownian diffusion processes that would drive them to their intended destination (Tsuda, et al., 2013).

Previous work has shown (Tong, et al., 2014) that salbutamol sulfate deliquesces at around 92\% relative humidity $(\mathrm{RH})$. Deliquescence describes the phase change of a crystalline solid to a saturated solution droplet using water collected from the surrounding air. Temperature can affect the RH level required to bring about deliquescence in hygroscopic substances but the effect varies between compounds (Lipasek, et al., 2013). Temperature also has a significant influence over the saturation vapour pressure of air (Law rence, 2005) so the air inside the lungs at $37^{\circ} \mathrm{C}$ and near- $100 \% \mathrm{RH}$ contains three times the concentration of water as outside air at similar $\mathrm{RH}$ and $20^{\circ} \mathrm{C}$ (Nave, 2004). However, temperature influences the kinetics of drug dissolution only, rather than the thermodynamic behaviour of solid particles, which remain relatively unchanged, and it is not expected to significantly impact hygroscopic properties.

The rate of deliquescence dictates the rate of adsorption of drugs across lung epithelia, since a given drug cannot be absorbed until it has fully dissolved (Bikiaris, 2011). This lends a time-critical aspect to drug delivery since solid particles in the lungs are removed over time by ejection via the mucociliary escalator in the ciliated regions of the lungs or partition into macrophages in the alveoli (Hardy \& Chadwick, 2000) and dissolution appears to be the rate-limiting step for the uptake of inhalable drugs (Bur, et al., 2010). If more of a given drug is removed in these manners before itis fully dissolved, a 
greater dose must be administered and the resultant side effects such as immunosuppression with corticosteroids (Lee, et al., 2012) and hypoalkaemia with salbutamol (Hung, et al., 1999) will have greater impacts on patient health.

On the other hand, as mentioned in the previous section rapid deliquescence can lead to an increase in particle size that makes it more difficult for drugs to reach deep into the airways. Finding optimal values for both particle size and hygroscopicity is important for providing patients with the most efficiently delivered treatment with the least side effects, and is the primary motivation for this series of experiments. Additionally, a better understanding of the hygroscopic properties of drug molecules

\section{Methods and Materials}

The combination of optical trap, Raman spectroscopy and model lung was first described in Tong et al 2014 (Tong, et al., 2014). The optical trap uses a counter propagating dual beam (CPDB) trap configuration first described by Rkiouak et al. (Rkiouak, et al., 2014) and deployed in several subsequent experiments (Tang, et al., 2014) (Jones, et al., 2015) (Hunt, et al., 2015). This trapping setup is remarkable because it is capable of stably trapping micron-sized solid particles of nonspherical geometry for periods of time up to several hours.

\subsection{Counter propagating dual beam optical trap}


1 The trapping beams were generated by a $1064 \mathrm{~nm} \mathrm{Nd:Yag} \mathrm{laser} \mathrm{(Ventus,} \mathrm{Laser} \mathrm{Quantum)} \mathrm{passed}$ through a beam splitter (Oz optics) and fibre-coupled into two single-mode fibres. Each fibre output was delivered to beam expansion and collimation optics before entering the objective lenses. The laser power at output was $15 \mathrm{~mW}$ from the top objective lens and $10 \mathrm{~mW}$ through the bottom objective lens (figure 2). The asymmetry in power ensured that trapped particles were driven closer to the optical focus plane of the bottom objective through which the Raman laser is passed, ensuring better focus on the resulting images (Rkiouak, et al., 2014). The foci of the lasers were positioned $~ 10$

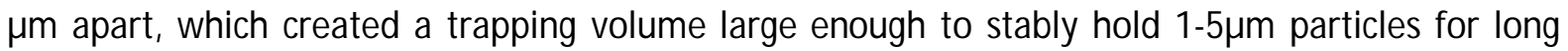
periods. Once all useful observations had been collected from a trapped particle, the particle was allowed to fall under gravity to the cover slip by blocking the $1064 \mathrm{~nm}$ trapping beams.

There are several reasons to prefer an optical trap to cover slip analysis. The most significant is that pharmaceutical aerosols are, until they reach the respiratory tract, suspended particles and attempts to recreate their conditions should be as close as possible. Interactions between collecting substrates and water can measurably alter the deliquescence point of hygroscopic particles (Eom, et al., 2014) with surfaces like glass reducing the deliquescence point of sodium chloride by $1.5 \%$ compared to a suspended particle. Previous work in our group has also observed changes in particle efflorescence upon a cover slip compared to optical trap. Any particle landing on a cover slip will have part of its surface in contact with the cover slip rather than exposed to the surrounding air (see figure 1), so a hygroscopic particle will form a water layer beginning with a halo around the contact point with the cover slip rather than across the surface dictated by the particle's geometry and density of hygroscopic sites. The shape of the resulting droplet and rate of adsorption will both be affected by the presence of a cover slip.

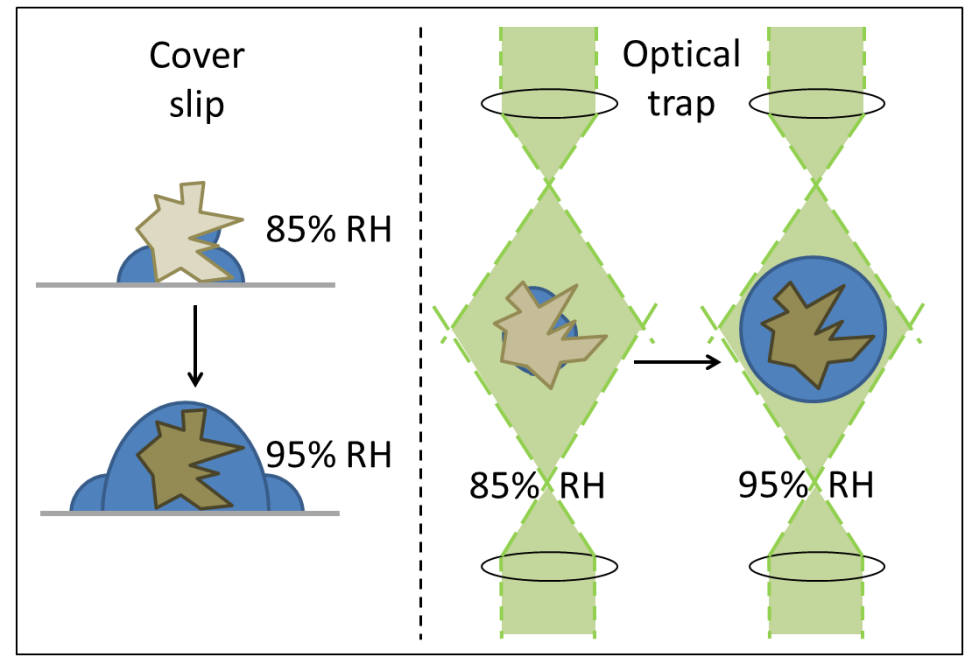

Figure 1. An illustration of the influence of coverslips on the formation of water layers on hygroscopic particles. Optical trapping allows particles to remain suspended as they deliquesce in a manner more representative of particles in vivo.

This is especially important in time-critical experiments such as those reported in this paper. Optical trapping represents the best current option for making detailed observations of physical and chemical changes on suspended particles in varying conditions, and yields better resolved Raman spectra than particles observed on a cover slip due to the removal of interfering spectral features associated with the composition of the cover slip. Optical trapping is typically superior for single particle spectroscopy 
1 when compared to other single particle levitation techniques, such as electrodynamic balances or acoustic trapping, because the optical setup ensures good alignment between the studied particle and

3 spectroscopic probe (Hargreaves, et al., 2010).

Optical trapping is easiest with spherical or spheroidal particles and droplets due to their symmetry

5 (Ashkin, 1992). While the setup used in this work has demonstrated the capacity to trap non-spherical particles for periods of an hour or longer (Rkiouak, et al., 2014) (Tong, et al., 2014), particles that are closer to spheres are still easier to trap for the same reasons.

\subsection{Raman Spectroscopy}

Raman spectroscopy is a powerful technique for examining the functional groups and intermolecular interactions of substances, requiring very small sample masses and no sample preparation (Hirschfeld $\&$ Chase, 1986) (Vankeirsbilck, et al., 2002) and making it ideal for the analysis of micrometer-scale drug particles. Raman spectroscopy has much lower signal-to-noise ratio than competing infrared analysis techniques because of the visible range detection region, and because the scattering wavelengths are separate from those of the excitation laser, so the technique can be effective with very small samples whose absorption would be indistinguishable against a standard FT-IR beam (PerkinElmer Inc, 2008). These experiments use a Raman setup which collects back-scattered photons along the same path as the excitation laser, but filtering the excitation photons with a Razoredge dichroic mirror and longpass edge filter combination (SemRock).

Raman scattering was generated using a 514.5nm Ar-ion laser (Innova 300C, Coherent), with a power of $4.3 \mathrm{~mW}$ measured at the laser focus. Each Raman spectrum was generated by a 30 second exposure to the $514.5 \mathrm{~nm}$ laser. This is longer than the residence time of particles in the respiratory system but is necessary to generate usable and reproducible spectra. These wavelength and power settings were selected based on previous experiments (Hunt, et al., 2013) as they were found to cause minimal heating of samples over long periods of exposure. Raman scattered light was collected in the region of $540-1830 \mathrm{~cm}^{-1}$.

Wavelength calibration of the Raman spectrometer was carried out using a cover slip with raised sides containing pure liquid toluene. The spectrum is collected from a focal point within the bulk liquid, away from the surface of the cover slip to avoid interference. The position of spectral peaks for toluene is well characterized and these are used as a reference for wavelength calibration.

\subsection{Artificial Lung Chamber \& Particle Imaging}




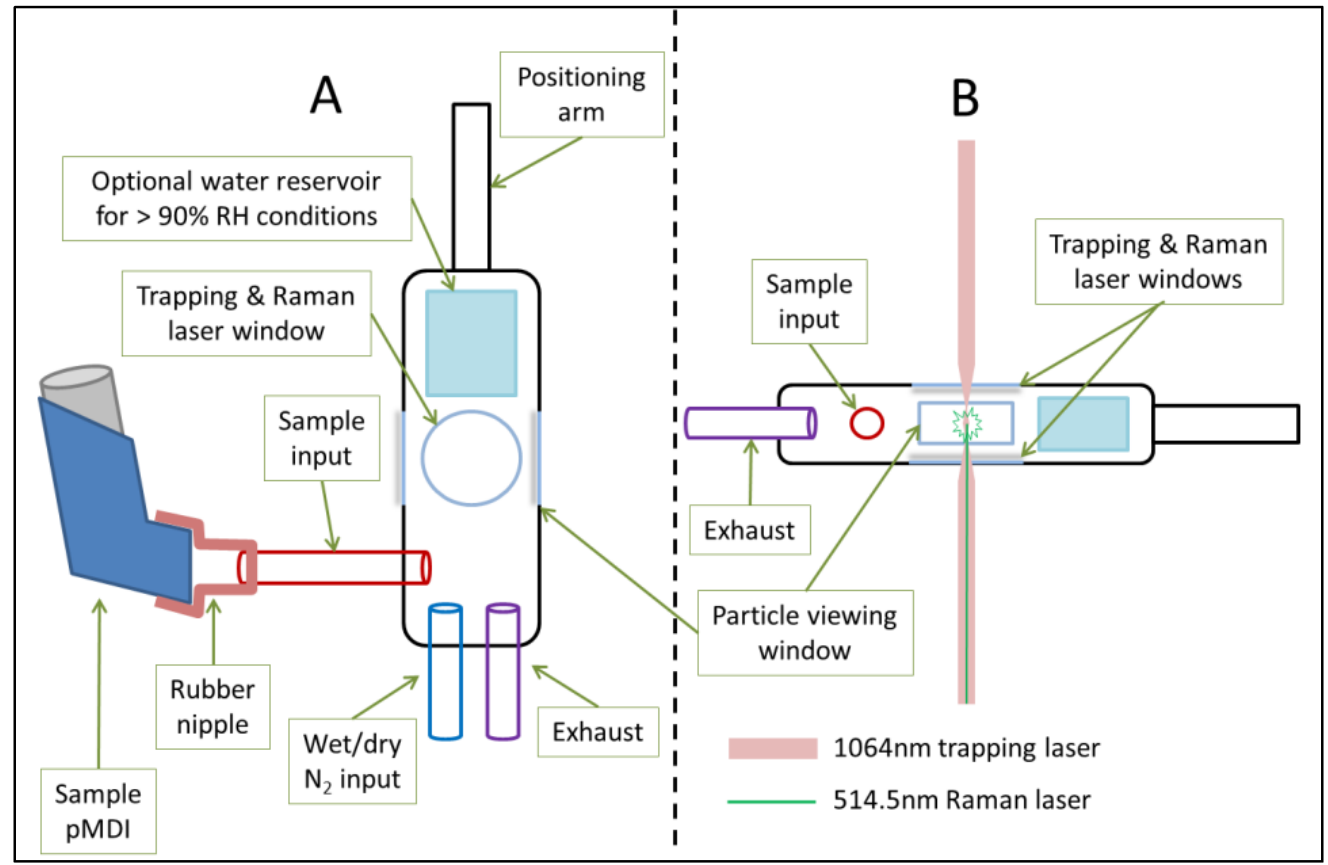

Figure 2 Top-down (A) and side (B) views of the artificial lung chamber (High RH conditions here defined as $>93 \% @ 20^{\circ} \mathrm{C}$ )

The artificial lung (figure 2) was an aluminium chamber of internal dimensions approximately $10 \times 2 \times$ $1 \mathrm{~cm}$, with borosilicate cover slip windows at the top and bottom to admit laser light and also at the sides to observe particles using a M itutoyo M Plan Apo 20x objective lens connected to a CCD camera (Princeton Instruments, Spec10), opposite an LED source (Comar Optics). A monitor attached to the CCD camera allowed users to observe particles passing around, through and into the optical trap.

RH and temperature were monitored using a Sensirion SHT-75 RH probe with a manufacturer-stated accuracy of $\pm 1.8 \% \mathrm{RH}$ and $\pm 0.3^{\circ} \mathrm{C}$. Raman spectra were collected within 3 minutes of reaching the desired $\mathrm{RH}$. This is significantly longer than the 10 seconds recommended by the medical community for inhalation, holding an exhalation of a pMDI dose but is necessary for adjusting RH accurately and for developing clear and reproducible spectra. RH levels were altered using $\mathrm{N}_{2}$ gas sourced from boiled off liquid nitrogen, using a flow rate of $200 \mathrm{~cm}^{3} /$ min through a Bronkhorst MV-301 mass flow controller. A lower flow rate of $100 \mathrm{~cm}^{3} /$ min was used for $\mathrm{RH}$ adjustment of the Salmeterol particles, since higher flow rates tended to dislodge the particles from the trap for reasons discussed in section 3.3. The input and exhaust ports were located on the same face of the cell in order to generate slow flow conditions around trapped particles and thus minimise turbulence that might dislodge the particle.

The gas was either run into the cell directly (low RH) or passed through a bubbler containing milli-Q grade deionized water before entering the cell (high $\mathrm{RH}$ ). For very high $\mathrm{RH}$ conditions, a water reservoir was added inside the chamber. While the bubbler could provide $\mathrm{RH}$ up to $\sim 90 \%$, the reservoir could generate $\mathrm{RH}$ as high as $93 \%$ at $30^{\circ} \mathrm{C}$ and up to $98 \%$ at $20^{\circ} \mathrm{C}$.

Salmeterol xinafoate, fluticasone propionate and ciclesonide were analysed at ambient temperature at high and low RH. Salbutamol sulfate was analysed both at ambient temperature and at more 
1 physiologically relevant temperatures by incubation of the microscope environment using Solent

2 Scientific incubator components.

$3 \quad 2.4 \mathrm{pMDI}$ injection

4 To dispense the aerosolised drug into the artificial lung chamber, a simple connector was built for the pMDI outlet involving a flexible rubber cap with a rigid $6 \mathrm{~mm}$ (internal diameter) PTFE tube protruding through it. The tube was connected to a similar tube on the side of the artificial lung by a short length of flexible silicone tubing. The chamber was washed sequentially in deionized water and methanol to

minimise potential cross-contamination with other drugs.

9 The propellant flow within the sample chamber carried material from each pM DI discharge into the 10 path of the trapping beam. Drug particles passing across the side viewing window were illuminated by 11 an LED and observed on a monitor. Scattering of the unfiltered trapping laser from a trapped particle 12 was viewed on the same monitor to indicate the positional stability of the particle.

13 Based on the stated mass per release of each drug, the density of the solid material (Zhejiang NetSun 14 Co., Ltd., 2010), the assumption that an average particle is solid and has a volume of approximately $1510 \mu \mathrm{m}^{3}$, a single release from each inhaler is estimated to deliver approximately $10^{6}$ to $10^{7}$ particles to 16 the chamber. However, many of these particles are lost by impaction onto the walls of the chamber. 17 A single trapped particle, which is at least $2 \mu \mathrm{m}$ in diameter, has sufficient material to generate a 18 Raman spectrum.

\section{$19 \quad 2.5$ SEM imaging}

20 Each drug was actuated onto a glass cover slip and coated with 10nm gold particles in a Polaron 21 SC7640 sputter coater. The cover slips were attached to Agar Scientific $25 \mathrm{~mm}$ double sided sticky 22 carbon tabs prior to imaging on a Philips XL30 ESEM FEG.

\subsection{Chemical Structures of the asthma drugs investigated}



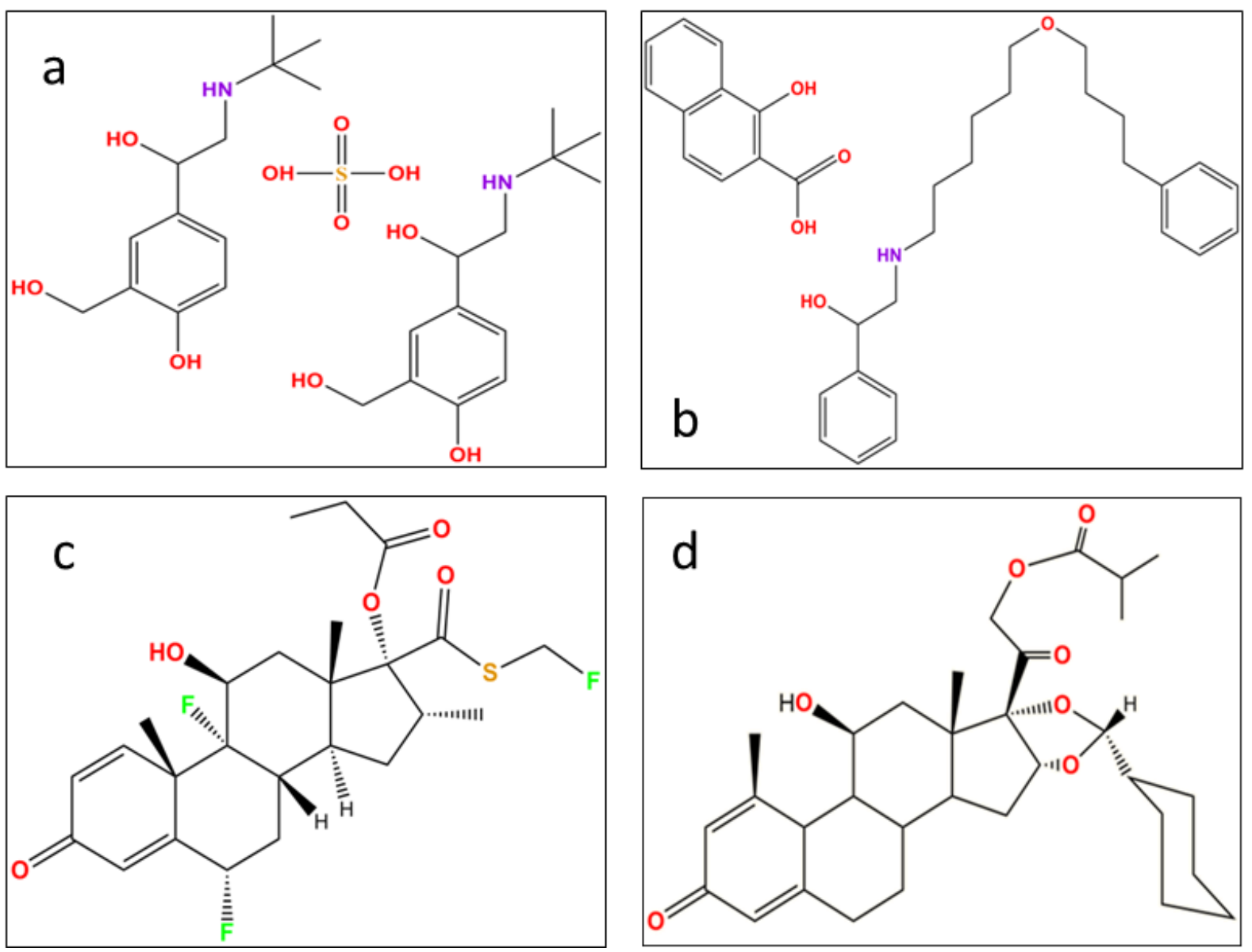

Figure 3 Chemical structures of single molecules of salbutamol sulfate (a), salmeterol xinafoate (b), fluticasone propionate (c), and ciclesonide (d)

Salbutamol sulfate particles were generated from a Salamol brand inhaler by Ivax Chemicals Itd. Salbutamol sulfate contains several polar groups and no long aliphatic chains, and its hygroscopic character has been documented (Tong, et al., 2014). Salmeterol xinafoate particles were produced from a "Serevent" brand inhaler produced by Cipla Ltd. Salmeterol also contains multiple polar groups but also a long aliphatic chain. Its hygroscopic properties are to be determined.

Fluticasone propionate, generated from a "flixotide" brand inhaler, is manufactured by GlaxoSmithKline, and ciclesonide particles were generated by a "Ciclohale" brand inhaler also by Cipla Ltd. Ciclesonide is produced under license from Takeda UKLtd. Fluticasone propionate and ciclesonide are both steroids and as such are relatively hydrophobic and are not expected to show hygroscopic properties.

\section{Results and Discussion}

\subsection{Thermodynamic Calculations of Particle Hygroscopicity}

Thermodynamic calculations of aerosol particle hygroscopicity were carried out using the Extended Aerosol Inorganics M odel (E-AIM) (Clegg, et al., 2001) (Engelhart, et al., 2011) (Ling \& Chan, 2008). EAIM is a thermodynamic model for predicting the water content of aerosol particles at different RHs. The model is appropriate for calculating the thermodynamic state of the drug aerosol for a given $\mathrm{RH}$, however, the model does not take into account the time dependent kinetic limitations of water uptake 
to the particle within the respiratory tract. Within E-AIM, model III is used and the UNIFAC model is chosen to calculate the water activities of the organic fraction of the investigated drugs within the particle at different RH. The UNIFAC model parameterizes the molecular composition of the organic fractions of the investigated drug particle using a combination of structural and functional groups (Wittig, et al., 2003). The calculation of water activities of the sulfate group within salbutamol sulfate is also described by Clegg (Clegg \& Brimblecombe, 1998). The type and quantity of UNIFAC parameters chosen to represent the four investigated drugs are provided in Table 1. It is noted in some cases exact matches for molecular composition, using UNIFAC, of the investigated drugs are not possible and in such cases the closest match was used. Standard dissociation constants for the carboxylic acid and amine functional groups were used. The model assumes that both salbutamol sulfate and salmeterol xinafoate dissociate into their respective ions dependent upon their dissociation constants. The formation of solid salts (salbutamol sulfate and salmeterol xinafoate) is disallowed since the activity products of the salts are unknown. Hence the modelled hygroscopicity provides an upper limit estimate.

Table 1. UNIFAC parameters used for thermodynamic modelling of the four investigated drugs. Note that the salmeterol xinafoate is modelled as two separate molecules: salmeterol and xinafoate. Also note that the sulphate in salbutamol sulphate is not modelled using UNIFAC hence its omission from the table.

\begin{tabular}{|c|c|c|c|c|c|}
\hline UNIFAC Group & Salmeterol & Xinafoate & Salbutamol & $\begin{array}{l}\text { Fluticasone } \\
\text { propionate }\end{array}$ & Ciclesonide \\
\hline Alkane (CH3) & - & - & 3 & 4 & 3 \\
\hline Alkane $(\mathrm{CH} 2)$ & 10 & - & 1 & 1 & 9 \\
\hline Alkane $(\mathrm{CH})$ & 1 & - & 1 & 4 & 6 \\
\hline $\begin{array}{l}\text { Alkene } \\
(\mathrm{CH}=\mathrm{CH})\end{array}$ & - & - & - & 1 & 1 \\
\hline Alkene $(\mathrm{CH}=\mathrm{C})$ & - & - & - & 1 & 1 \\
\hline $\begin{array}{l}\text { Aromatic } \\
\text { carbon }(\mathrm{ACH})\end{array}$ & 8 & 6 & 3 & - & - \\
\hline $\begin{array}{l}\text { Aromatic } \\
\text { carbon }(A C)\end{array}$ & 4 & 4 & 3 & - & - \\
\hline Alcohol $(\mathrm{OH})$ & 3 & 1 & 3 & 1 & 1 \\
\hline $\begin{array}{l}\text { Carboxylic } \\
\text { acid }(\mathrm{COOH})\end{array}$ & - & 1 & - & - & - \\
\hline $\begin{array}{l}\text { Carbonyl } \\
\text { (CH2CO) }\end{array}$ & - & - & - & 2 & 2 \\
\hline Ether $(\mathrm{CH} 2 \mathrm{O})$ & 1 & - & - & - & - \\
\hline Ether (CHO) & - & - & - & - & 2 \\
\hline $\begin{array}{l}\text { Secondary } \\
\text { amine } \\
(\mathrm{CH} 2 \mathrm{NH})\end{array}$ & 1 & - & 1 & - & - \\
\hline
\end{tabular}




\begin{tabular}{|l|l|l|l|l|l|}
\hline $\begin{array}{l}\text { Acetate } \\
(\mathrm{CH} 2 \mathrm{COO})\end{array}$ & - & - & - & 1 & 1 \\
\hline $\begin{array}{l}\text { Fluoroalkane } \\
(\mathrm{CF})\end{array}$ & - & - & - & 3 & - \\
\hline
\end{tabular}

1

2

3

4

5

6

7

8

9

10

The output from E-AIM allows for the prediction of the drug molecule hygroscopicity (Clegg, et al., 2001) (Engelhart, et al., 2011) (Ling $\&$ Chan, 2008). Figure 4 shows the mass growth factors for the four investigated drugs. M ass growth factor is defined as the mass increase, for a given $\mathrm{RH}$, normalized to the dry mass. It can be seen that Figure 4 predicts two distinct types of interaction. The beta- 2 agonists (salbutamol sulfate and salmeterol xinafoate) contain a higher proportion of hydrophilic groups and are thus predicted to be strongly hygroscopic, while the more lipophilic steroids (ciclesonide and fluticasone propionate) are expected to collect little water from the air even under near water saturated conditions. It is noted, that the bulk thermodynamic calculations in E-AIM do not take into account the crystal structure of solid particles which may block access to hydrophilic sites and prevent otherwise hydrophilic molecules from interacting with water in the air. Furthermore, the model runs do not take into account possible deliquescent barriers to water uptake due to the lack of product activity data.

Ferron's kinetic model (Ferron, 1977), as used in the International Commission on Radiological Protection (ICRP, 1994) provides a parameterization with which to estimate of the time dependent growth of hygroscopic particles. pMDI particles are typically generated in the size range $2-5 \mu \mathrm{m}$ to optimally deliver drugs to the central regions of the lung. The Ferron model suggests that $a$ hygroscopic particle of initial size of $2-5 \mu \mathrm{m}$ diameter will reach approximately $80-50 \%$ of its equilibrium size, respectively, within a typical 2-3 s long inhalation.

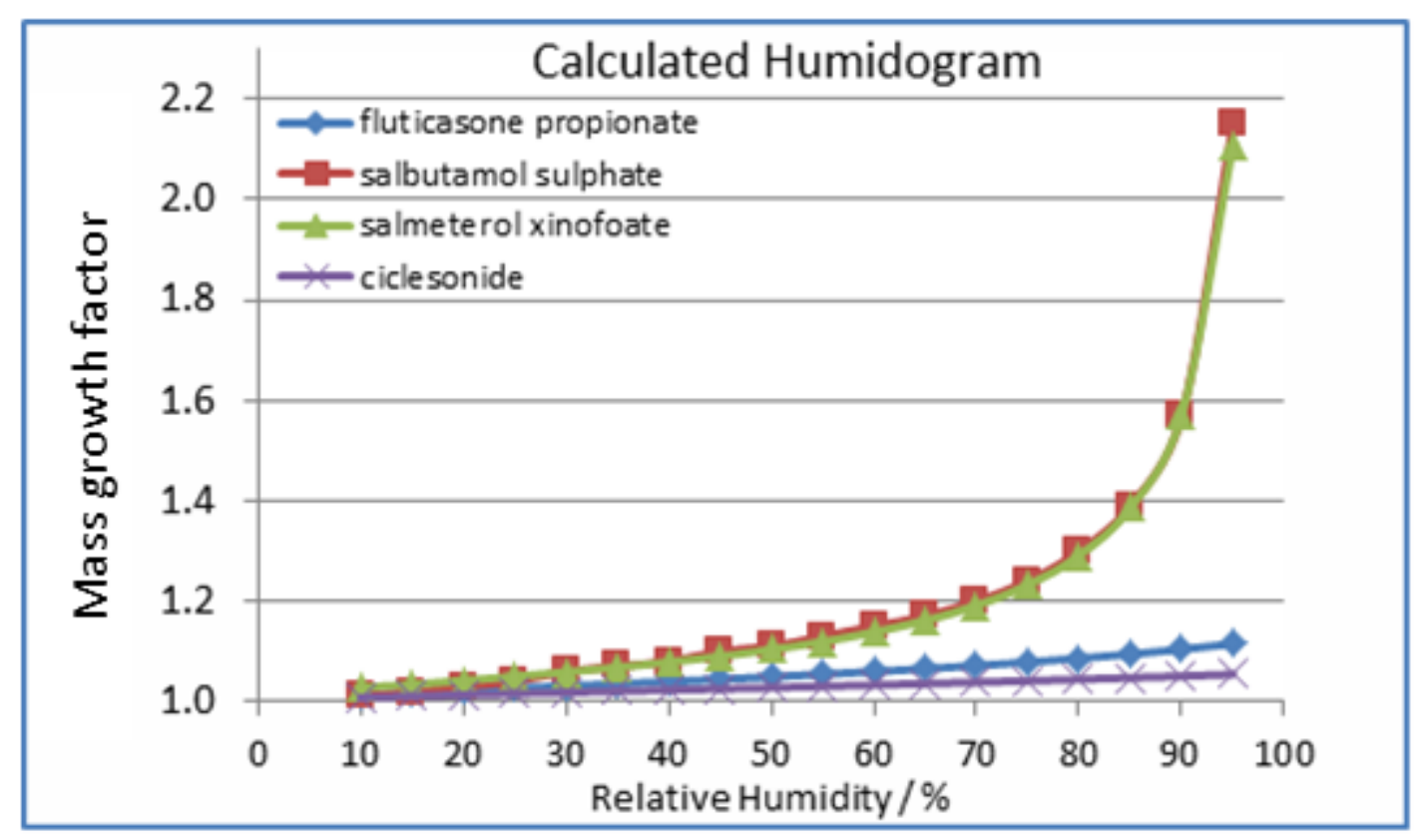

Figure 4 Influence of relative humidity on particle diameter predicted from chemical bonding 


\subsection{Drug Particle Crystallography}

The Mercury 3.6 program (M acrae, et al., 2006) was used to simulate the crystal structure of all drugs whose structures had been added to the Cambridge Structural Database run by the Cambridge Crystallographic Data Centre (CCDC, 2015).

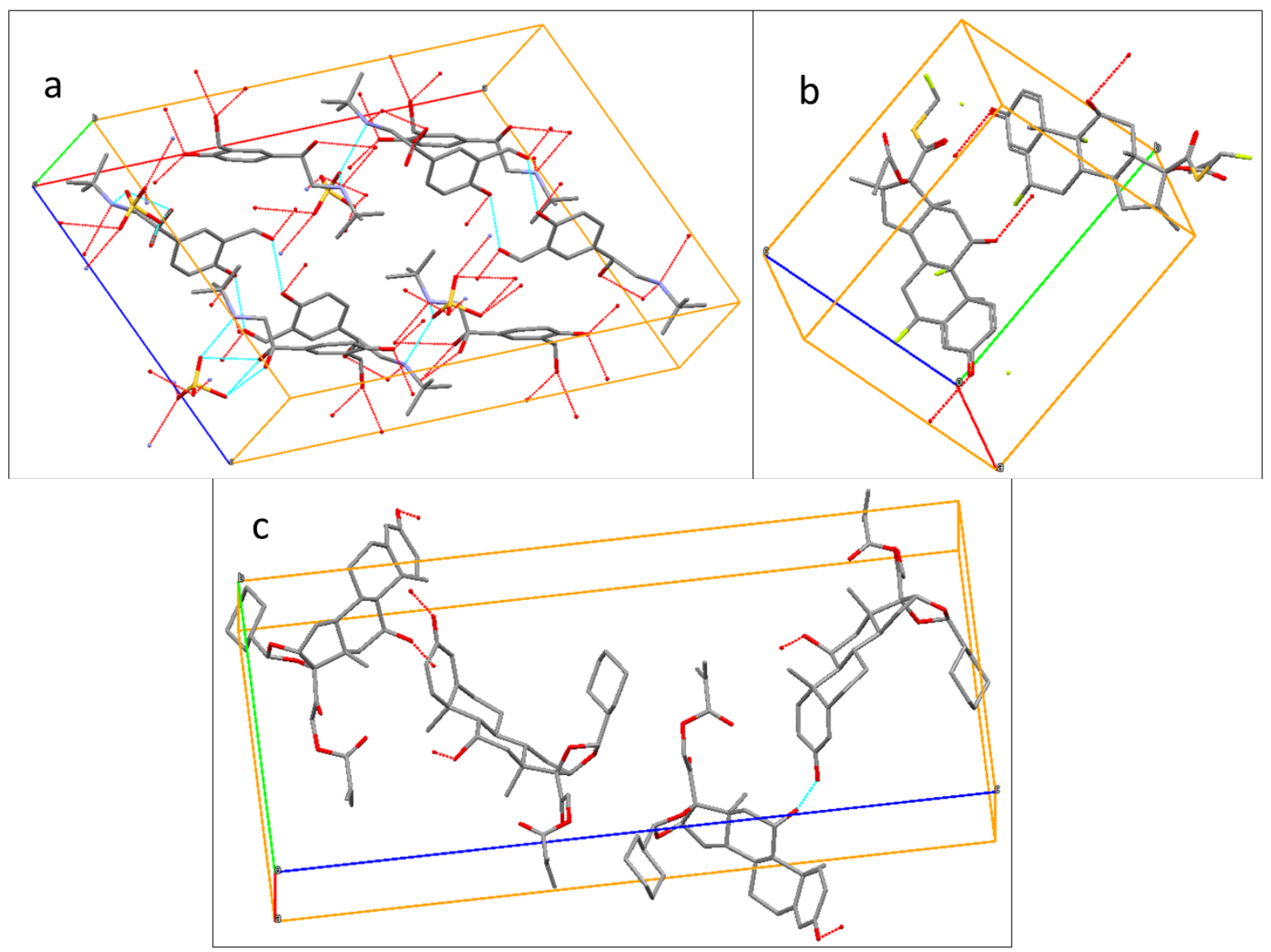

Figure 5 M odel unit cells of salbutamol sulfate (a), fluticasone propionate (b), and ciclesonide (c). Salmeterol xinafoate's unit cell was not available at time of writing. Hydrogen bonding within the unit cell is illustrated with a cyan line, while hydrogen bonding external to the unit cell (thus contributing to hygroscopic behaviour) are illustrated with red dotted lines.

The chemical structure of salbutamol sulfate (figure 5a) shows hydrophilic sites across the molecule. The most likely crystal form generated by rapid solvent evaporation in air was first described in 1978 (Leger, et al., 1978), with an 8 molecule unit cell (figure 5a) that shows hydrogen bonding sites on every face. Hygroscopic behaviour is inferred from this structure and has been demonstrated in previous experiments at room temperature (Tong, et al., 2014).

Salmeterol is not found in the Cambridge Structural Database. Solid structures are variously described as either amorphous, or needle-like or plate-like crystals depending on the exact conditions of manufacture (York \& Hanna, 1994) (Barjoan \& Clotet, 2009). Salmeterol xinafoate is bound together by hydrogen bonding of the $\delta$-positive amine group on salmeterol to the $\delta$-negative carboxylic acid group on the xinafoic acid. The two groups are expected to cancel their respective charges, leaving few hydrophilic sites open to interaction with water while the particle is in a solid state. 
1 As a steroid, fluticasone is expected to be lipophilic (Lipworth \& Jackson, 2000). The structure of

fluticasone (figure $5 b$ ) does have a number of polar groups. However, the documented crystal structure (Cejka, et al., 2005) describes a plate-like structure with any hydrogen bonding occurring along the plane of growth (figure $5 b$ ) resulting in water interaction only along edges, and likely to result in little or no hygroscopic behaviour.

Ciclesonide (figure 5c) is found as either needle-like (Phull, et al., 2012) or needle-like and spherulitic crystals as well as amorphous solids (Feth, et al., 2007) depending on solvent type and evaporation time. Ciclesonide has multiple polar groups but the model unit cell described by Feth et al describes most of the oxygens arranged inside the crystal with the hydrophobic sites facing outward. Limited hydrogen bonding due to the hydroxyl and ketone groups on adjacent molecules have the potential to attract water molecules to crystal faces, but the hydrophobic nature of the rest of the exposed molecule implies that hygroscopic behaviour is unlikely.

\subsection{SEM imaging and Trapping Logistics}
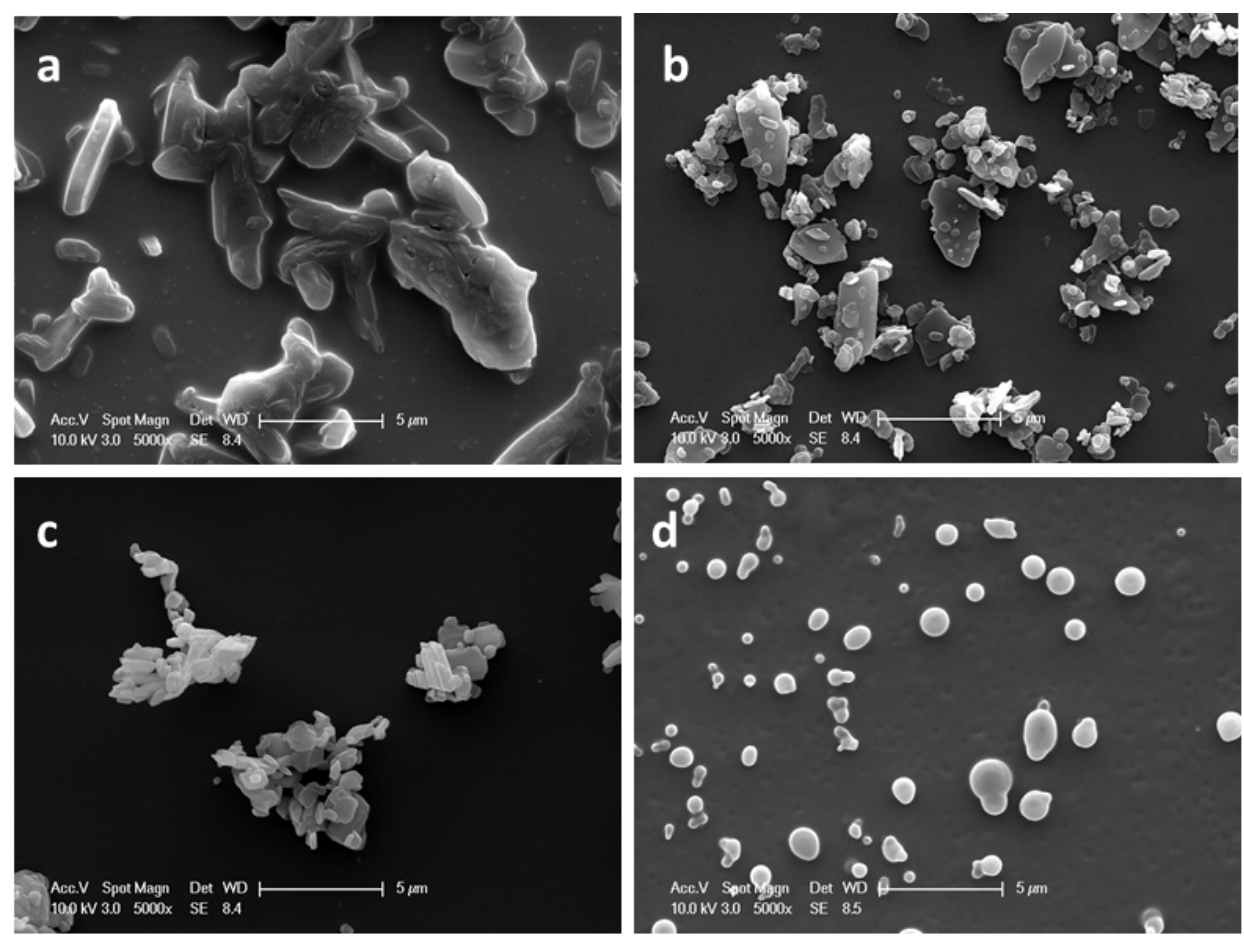

Figure 6 SEM images of: (a) salbutamol sulphate, (b) salmeterol xinafoate, (c) fluticasone propionate $\&$ (d) ciclesonide

SEM images of the drug particles were collected under dry conditions in order to determine shape and ease of capture. The likelihood of a particle being successfully caught in the optical trap is dictated by both particle shape and the number of particles generated per release. Salbutamol sulfate had been optically trapped previously on the same apparatus (Tong, et al., 2014). The thick, needle like shape of salbutamol sulfate particles (figure $6 a$ ) is well suited to entrapment for reasons detailed in section 2.4, and the $100 \mu \mathrm{g}$ per release dose of the available inhalers resulted in a successfully suspended particle roughly once for every two releases. Salmeterol xinafoate was significantly harder to trap and retain than the others due to a combination of its low dose (20 $\mu \mathrm{g}$ per release) and flat, platelike aggregate structure (figure $6 \mathrm{~b}$ ). Fluticasone has a similar crystal structure to salmeterol but a much higher dose ( $250 \mu \mathrm{g}$ per release) and was more reliably trapped than salbutamol sulfate. Ciclesonide 
1 was similar in trapping frequency to fluticasone since its lower dose (160 $\mu \mathrm{g}$ per release) was balanced

2 by a more spherical particle shape (figure $6 \mathrm{~d}$ ).

\section{$3 \quad 3.4$ Raman spectrum changes from hygroscopic properties and additional compounds}

$4 \quad$ Hydrogen bonding with water molecules adjacent to the polar groups of organic molecules expands 5 the range of vibrational energy states that can generate Raman scattering photons. This effect allows

6 water uptake by hygroscopic particles to be monitored by Raman spectroscopy.

7 All four drugs use hydrofluoroalkane HFA 134a/Norflurane as a propellant. The salbutamol and 8 ciclesonide inhalers also report anhydrous ethanol among their ingredients. Norflurane contains four 9 C-F bonds, each of which generate a distinctive Raman scattering peak at $1234 \mathrm{~cm}^{-1}$. This peak is not 10 expected to be visible in the Raman spectra of the drug molecules, apart from Fluticasone which has $113 \mathrm{C}-\mathrm{F}$ bonds of its own, due to Norflurane's low boiling point $\left(-26.5^{\circ} \mathrm{C}\right.$, (Lide, 1991)) at atmospheric 12 pressure causing all of the propellant to boil off before readings can be collected. The spectra collected 13 from particles other than fluticasone do not show peaks in the C-F stretching region, which implies 14 that all propellant boils off before the particles are scanned.

$15 \quad 3.5$ Salbutamol sulfate / Salamol ${ }^{\mathrm{m}}$

\section{$16 \quad 3.5 a$ Raman spectra and structural information}

17 Each salbutamol molecule contains a single phenol group, two aliphatic hydroxyls and a secondary 18 amine. One molecule of salbutamol contains two ionised salbutamol molecules bound to a single sulfate group. The $\mathrm{S}=0$ symmetric stretches on the sulfate show a small but distinctive peak at 1154 $\mathrm{cm}^{-1}$. The largest peaks in the salbutamol spectrum correspond to $-\mathrm{CH}$ wagging at $656 \mathrm{~cm}^{-1}$, aromatic ring vibration at $752 \mathrm{~cm}^{-1}, \mathrm{C}-\mathrm{C}-\mathrm{O}$ stretches in relation to the aliphatic hydroxyls at $784 \mathrm{~cm}^{-1}$, asymmetric hydroxyl stretches at 969, 977 and $1008 \mathrm{~cm}^{-1}$, phenyl ring vibrations at 1059 and $1074 \mathrm{~cm}^{-1}$, a prominent $\mathrm{CH}$ stretch at $1257 \mathrm{~cm}^{-1}$ (this bond can be found in figure 3 just above the ring) $\mathrm{CH}_{2}$ and $\mathrm{CHOH}$ vibrations again from the aliphatic hydroxyls at $1360 \mathrm{~cm}^{-1}$, a broad ring stretching peak around $1450 \mathrm{~cm}^{-1}$ followed by a $\mathrm{CH}_{2}-\mathrm{N}$ amine peak at $1463 \mathrm{~cm}^{-1}$, and finally a strong peak at $1615 \mathrm{~cm}^{-1}$ corresponding to the phenolic $\mathrm{C}-\mathrm{OH}$ stretch. All of these peaks (figure 7) correspond well with those found in the literature (Ali, et al., 2009). 


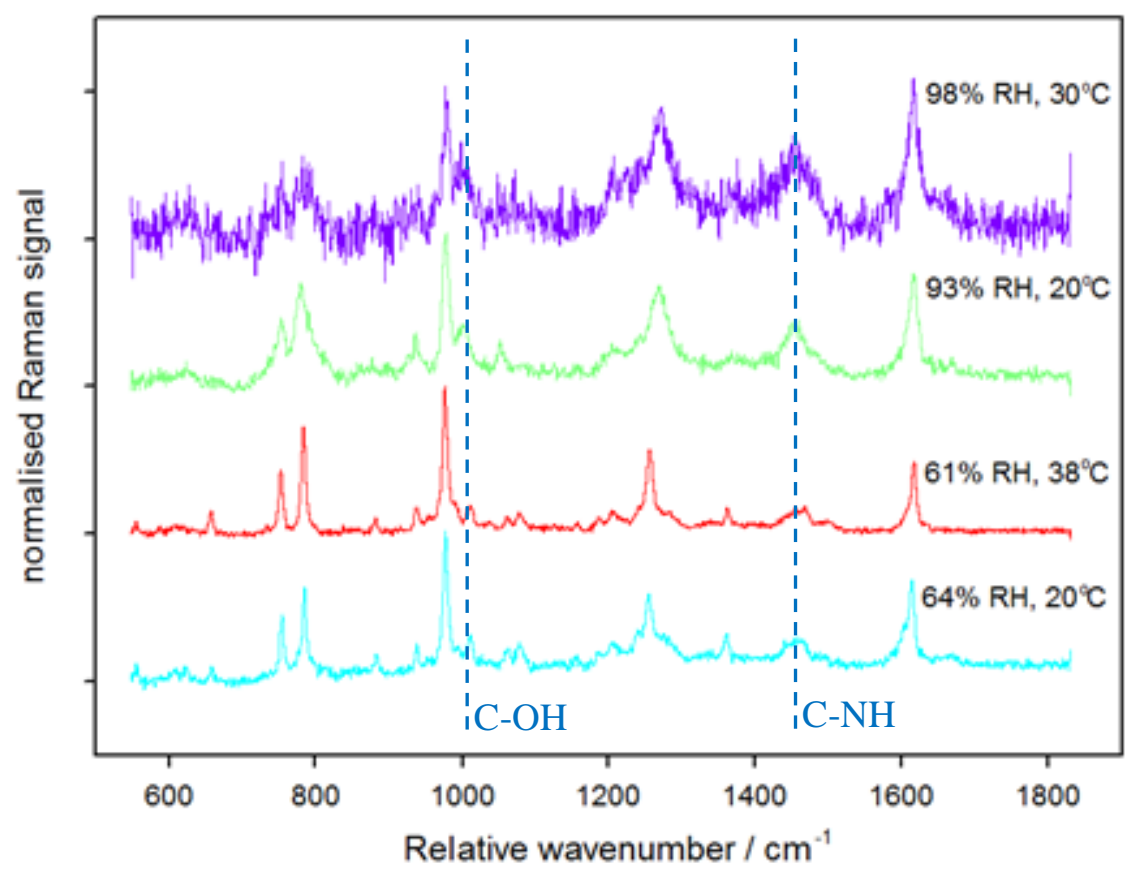

Figure 7 Raman spectra of optically trapped salbutamol sulfate particles at a range of RH and temperatures. Above salbutamol's deliquescence point of $92 \% \mathrm{RH}$, peak broadening is visible at the $\mathrm{C}-\mathrm{OH}$ peak at $1008 \mathrm{~cm}^{-1}$ and at the $\mathrm{C}-\mathrm{NH}$ peak at $1463 \mathrm{~cm}^{-1}$, signifying water interaction with the bonds.

$\mathrm{RH}$ above 92\%, the deliquescence point identified by Tong et al (Tong, et al., 2014), could not be maintained at physiological temperature $\left(37^{\circ} \mathrm{C}\right)$ with the available equipment, so measurements were taken at $30^{\circ} \mathrm{C}$ - the highest temperature at which $>92 \% \mathrm{RH}$ could be maintained. The particle trapped at $98 \% \mathrm{RH}$ and $30^{\circ} \mathrm{C}$ was small, hence the poorer signal/noise ratio. The contrast between the relatively dry and relatively wet particles is clear to see as the peaks corresponding to hydrophilic bonds in the wet particles are broader, and some peaks such as the hydroxyl peak at $1008 \mathrm{~cm}^{-1}$ and the amine peak at $1463 \mathrm{~cm}^{-1}$ are more pronounced.

The spectral traces, recorded at similar $\mathrm{RH}$ but under contrasting temperatures, are very similar. Within the temperature range investigated $\left(20-38^{\circ} \mathrm{C}\right)$, there are no observable temperature effects upon particle deliquescence. The deliquescence $\mathrm{RH}$ is measured to be ca. $92 \% \mathrm{RH}$ in agreement with the measurement of Tong et al (Tong, et al., 2014). This implies that the temperature gradient experienced in the trajectory from pMDI to lung is likely to be unimportant in determining particle hygroscopicity; $\mathrm{RH}$ is the dominant determinant of particle hygroscopicity.

The modelling results from E-AIM suggested that salbutamol sulfate would show significant hygroscopicity if a deliquescence phase transition occurred. The experimental results confirm this model prediction. The presence of a phase transition and significant water uptake is in line with the high reported solubility of salbutamol sulfate (14.1g/L, (Walkowsky \& He, 2003).

\subsection{Salmeterol xinafoate / Serevent ${ }^{T m}$}

\section{6a Raman spectra and structural information}

Salmeterol xinafoate contains several aromatic rings, an ether group, a benzoic acid and a secondary amine. Benzoic acid is distinct from both aromatic rings and carboxylic acids due to the increased 
1 conjugation (Kwon, et al., 1994) and shows distinctive peaks in the solid state at $1627 \mathrm{~cm}^{-1}, 994 \mathrm{~cm}^{-1}$ and $788 \mathrm{~cm}^{-1}$. These peaks are all present in our spectra (figure 8). Ring stretches are clearly visible at $1580-1616 \mathrm{~cm}^{-1}, 1400-1420 \mathrm{~cm}^{-1}$ (the multiple strong peaks denoting ring stretches shifted by the various adjacent functional groups) and symmetric ring stretches are visible at 1000-1028 cm-1, 1215 and $1257 \mathrm{~cm}^{-1}$. A strong amine vibration peak is visible at $1204 \mathrm{~cm}^{-1}$. A sharp peak at $730 \mathrm{~cm}^{-1}$ corresponds to rotational peaks from $\mathrm{CH}_{2}$ groups, as would be expected by a molecule with a long aliphatic chain like salmeterol. The ether group can be identified by small peaks at 554 and $1145 \mathrm{~cm}^{-}$

8 1. These spectra correspond well with previously published, well-defined Raman spectra (Ali, et al., 9 2008a).

Repeated exposure to the Raman laser caused some fluorescence effects in salmeterol xinafoate particles, so each spectrum had to be recorded on a freshly captured particle. The Raman laser was blocked except during the collection of spectra in order to minimise the effect. The fluorescence activity that occurs in salmeterol xinafoate after prolonged exposure to the Raman laser may possibly be avoided in future experiments by using a longer excitation wavelength.

\section{5b Impact of RH on salmeterol spectra}

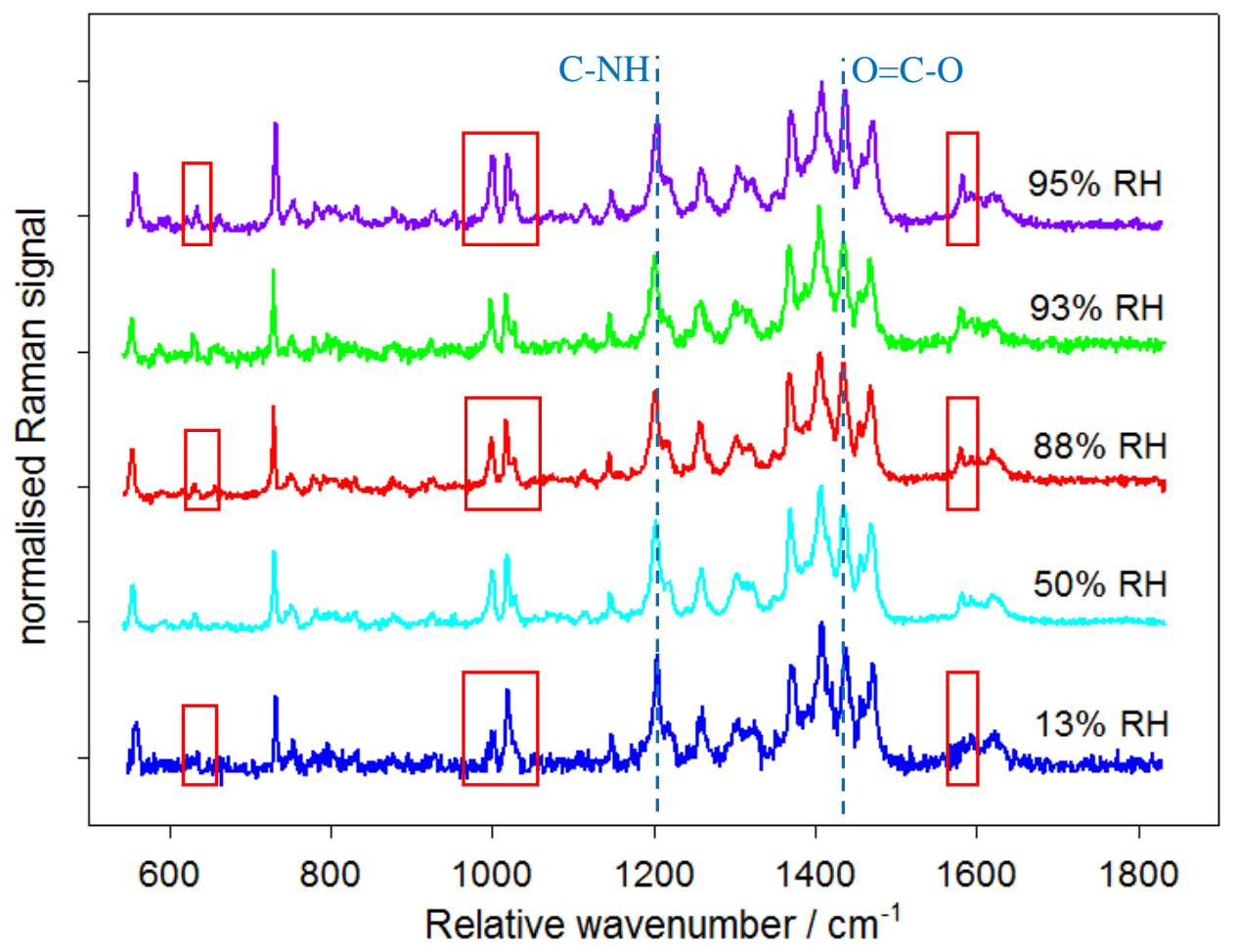

Figure 8 Raman spectra of salmeterol xinafoate at a range of RH values. Even at 95\% RH, the amine vibrational peak at $1204 \mathrm{~cm}^{-1}$ and carboxylic acid stretching peak at $1420 \mathrm{~cm}^{-1}$ do not show signs of broadening, contrary to the predicted behaviour modelled by E-AIM. Intensity changes on the aromatic ring stretches at different $\mathrm{RH}$ are highlighted in red.

According to the Raman spectra collected in figure 8, salmeterol xinafoate does not demonstrate any visible broadening around peaks corresponding to either salmeterol's amine group or the carboxylic acid group on its xinafoic acid partner upon RH enhancement. This suggests that the salt does not undergo a deliquescent phase transition. The modelling results from E-AIM suggested that salmeterol 
1 xinafoate would show significant hygroscopicity if a deliquescence phase transition occurred. The observed lack of deliquescence is in line with the low predicted solubility of salmeterol xinafoate (22.6 mg/L according to ALOGPS (Tetko, 2001)).

The hygroscopic behaviour of salmeterol xinafoate, as predicted by E-AIM , may be limited by the steric 5 hindrance of the hydrophilic sites by hydrophobic structures arranged around them in solid crystals.

6 The relative enhancement of peaks corresponding to aromatic ring stretches at 650, 1000 and 1580

$7 \mathrm{~cm}^{-1}$ imply some interaction with water around some or all of the aromatic rings in salmeterol 8 xinafoate at $>88 \% \mathrm{RH}$. Most likely, the presence of the hydroxyl and carboxylate groups on the 9 aromatic xinafoate section of the drug enhances water interaction.

\subsection{Fluticasone propionate / Flixotide}

\section{3.4a Raman spectra and structural information}

12 Fluticasone contains several distinctive bonding types that would be expected to yield distinctive peaks in any resulting Raman spectra: a phenone, an ester, a thioether and three C-F bonds across the molecule. Fluticasone has been imaged by Raman spectroscopy previously and its spectra interpreted in depth (Ali, et al., 2008b) (Rogueda, et al., 2011) (Theophilus, et al., 2006) (Wang, et al., 2014), which provides useful references for the spectra generated here.

The raw fluticasone propionate spectra contained a very sharp and strong peak at $640-650 \mathrm{~cm}^{-1}$. This peak was not observed in other spectra in the literature. We believe this peak to be an artefact caused by second harmonic resonance effect from the $1064 \mathrm{~nm}$ trapping laser. Confirmation of the spectral artefact was achieved by measuring spectra of fluticasone propionate recorded on the cover slip without the trapping laser present. These spectra did not contain the peak. We have removed this artificial peak from the spectra shown in Figure 9.

The strongest peak in the spectrum of fluticasone is the $\mathrm{C}=0$ vibration at $1659 \mathrm{~cm}^{-1}$, followed by the $\mathrm{CH}_{3}$ symmetric stretch (there are $4-\mathrm{CH}_{3}$ groups in Fluticasone) at $1606 \mathrm{~cm}^{-1}$. $-\mathrm{CH}_{2}$ and $-\mathrm{CH}$ stretches occur at around 1380 and $1330 \mathrm{~cm}^{-1}$ respectively and highly distinctive C-F and S-C-F bands occur at $1234 \mathrm{~cm}^{-1}$ and $1022 \mathrm{~cm}^{-1}$. Fluticasone is the only compound among the samples that contains a C-F bond, and generated the only spectra showing C-F stretching peaks. This implies that that in all samples the Norflurane propellant had fully evaporated prior to analysis. The phenone group registers as an $\mathrm{OOH} / \mathrm{CCH}$ aromatic deformation peak at $888 \mathrm{~cm}^{-1}$. A small $\mathrm{C}-\mathrm{H}$ wagging peak can be seen at around $700 \mathrm{~cm}^{-1}$.

\section{4b Impact of RH on fluticasone spectra}




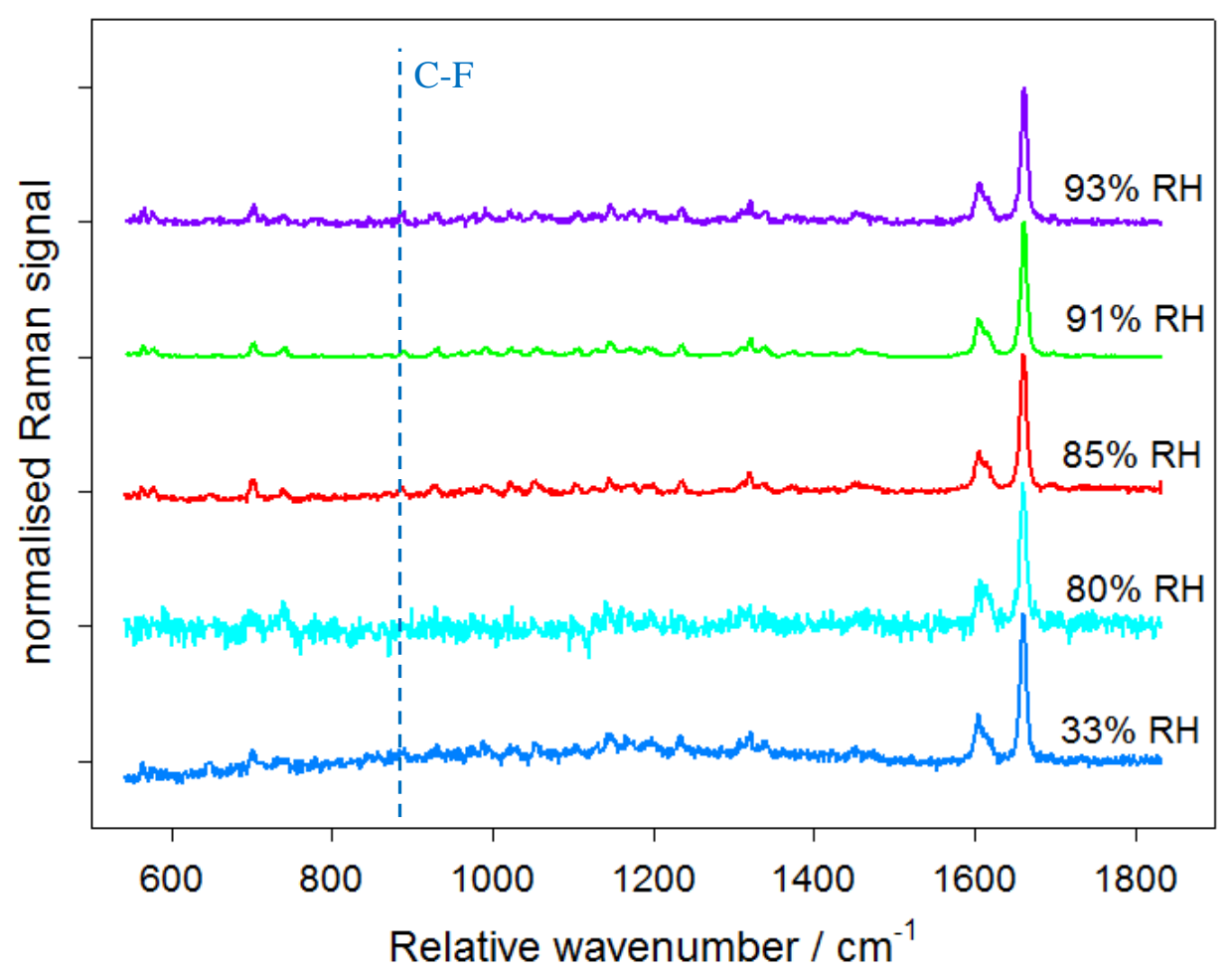

Figure 9 Raman spectra of fluticasone propionate at a range of RH values. The C-F stretching peak at $888 \mathrm{~cm}^{-1}$ is present in this spectrum but not the others, confirming that the Norflurane propellant discussed in section 3.4 has boiled off

5 The spectrum collected at $80 \%$ RH was from a small particle- around $1 \mu \mathrm{m}$ in diameter. This accounts 6 for the greater noise in the signals. Otherwise, no peaks are displaced or strongly deformed by the rise 7 in relative humidity. Fluticasone shows no signs of hygroscopic behaviour, in agreement with the 8 results from E-AIM. Water solubility is low (11.4 mg/L) as predicted by ALOGPS (Tetko, 2001).

\subsection{Ciclesonide / Alvesco ${ }^{\text {Tm }}$}

\section{5a Raman spectra and structural information}

Ciclesonide (Feth, et al., 2008) has a diverse selection of functional groups, which generates a complicated Raman spectrum. The largest peak at $1654 \mathrm{~cm}^{-1}$ (figure 10) represents the stretching vibration of an $\alpha, \beta$-unsaturated carbonyl, while the adjacent peak at $1601 \mathrm{~cm}^{-1}$ shows the neighbouring $\mathrm{C}=\mathrm{C}$ bond. Ciclesonide contains four $-\mathrm{CH}_{3}$ groups and this corresponds to another large, broad peak at $1443 \mathrm{~cm}^{-1}$. The three ether bonds generate another large peak at $1112 \mathrm{~cm}^{-1}$, and the single ester linkage appears at $1242 \mathrm{~cm}^{-1}$. Ciclesonide has a single hydroxyl group attached to a sixmembered saturated ring, and a matching "cyclic alcohol" stretch appears at $1029 \mathrm{~cm}^{-1}$. The C-C stretches of the two saturated six-membered rings are found at $963 \mathrm{~cm}^{-1}$. Multiple small peaks around $800-900 \mathrm{~cm}^{-1}$ represent ring deformation in the phenol group adjacent to the saturated rings. Another region of small peaks around $1330 \mathrm{~cm}^{-1}$ corresponds to the various symmetric and antisymmetric stretches of the isopropyl group.

\section{5b Impact of RH and Temperature on Ciclesonide Spectra}




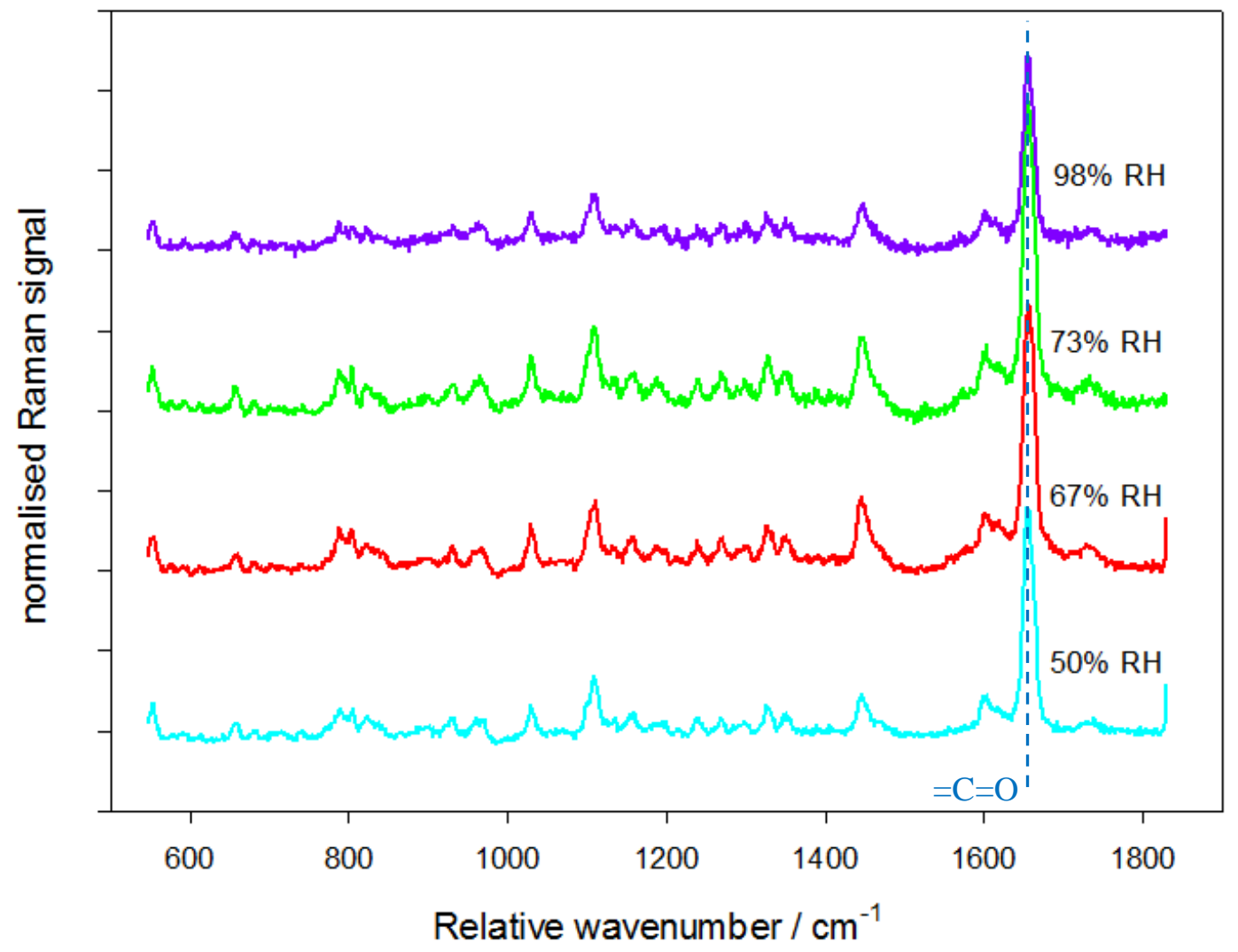

Figure 10 Raman spectra of ciclesonide at a range of RH values. The spectra show no signs of hygroscopic behaviour at up to $98 \% \mathrm{RH}$.

4 As a steroid, ciclesonide is not very hydrophilic and does not contain many polar groups. The crystal structure shows very little opportunity for water uptake on surfaces, and E-AIM predicts that ciclesonide has the lowest hygroscopic potential of any of the drugs analysed. Calculated water solubility is also the lowest of all the drugs $(1.57 \mathrm{mg} / \mathrm{L}$, (Tetko, 2001)). It would not be expected to show hygroscopic behaviour, and no such behaviour was observed in the Raman spectra compiled in figure 10.

\subsection{Specific advantages and limitations of procedure to drug delivery}

The advantages of this setup and analytical technique to the examination of inhalable drugs do merit some discussion in addition to the general benefits of optical trapping over cover slip analysis documented in section 2.1. The current setup can monitor particle size with an external camera as well as directly monitoring water interactions with hydrophilic functional groups on particles by examining the Raman spectrum. On-board RH monitoring can determine deliquescence points for new drugs, or verify those of existing drugs, to a high degree of accuracy, factoring in the crystal structures of particles as well as their chemical structure in a manner that is difficult to reproduce with software modelling alone. At present, the main limitation of the technique is the length of time required to collect each Raman spectrum which is longer than the pMDI inhalation cycle. 
1 This series of experiments has demonstrated a viable technique for examining individual particles of inhalable drugs supplied by pM DIs. With little modification, such as by attaching a vacuum pump to

3 the outlet port of the sample chamber, this experimental setup may also be used to examine single 4 particles from DPI devices.

5 The Raman spectra of four optically trapped drug particles (salbutamol sulfate, salmeterol xinafoate, 6 fluticasone propionate and ciclesonide) were measured within a model lung. The model lung allowed 7 for modification of local $\mathrm{RH}$ to test the drugs for hygroscopic behaviour, while the optical trap 8 eliminated any surface effects from water droplets forming around a solid particle on a cover slip. 9 Raman spectroscopy allowed for the direct observation of the hydrogen bonding with water in hydrophilic groups, where the broadening of peaks indicates hygroscopicity.

Spectral peak broadening was observed in salbutamol sulfate particles above their deliquescence point at $92 \% \mathrm{RH}$, at room temperature and more physiologically relevant temperatures, while spectra remained similar to dry particles at lower $\mathrm{RH}$ regardless of temperature within the observed range. Salmeterol xinafoate shows some spectral changes to the intensities of the peaks corresponding to its aromatic rings, but does not show any changes to the more hydrophilic functional groups which is interpreted as no deliquescence at $\mathrm{RH}$ up to $95 \%$. Fluticasone propionate and ciclesonide show no hygroscopic properties at all, as would be expected with their lipophilic composition, low water solubility and the modelled particle growth factors generated using the E-AIM model.

\section{Acknowledgements}

M KK is thankful to the EPSRC for the Career Acceleration Fellowship (EP/I003983/1). ND thanks NERC for a personal studentship. M K was supported by ERC grant 279405. We are thankful to the

STFC for a programmed access grant LSF1207 (FLIM OLA).

\section{Works Cited}

25 Ali, Edwards, Kendrick \& Scowen, 2008b. Vibrational spectroscopic study of fluticasone propionate. Biomolecular Spectroscopy, pp. 244-247.

Ali, Edwards, Kendrick \& Scowen, 2009. Vibrational spectroscopic study of salbutamol hemisulphate. Drug Testing and Analysis, pp. 51-56.

Ali, et al., 2008a. Vibrational spectroscopic characterisation of salmeterol xinafoate polymorphs and a preliminary investigation of their transformation using simultaneous in situ portable Raman spectroscopy and differential scanning calorimetry. Analytica Chimica Acta, pp. 103-112. regime. Biophysical Journal, pp. 569-582. 
Bell \& Newman, 2007. The rejuvenated pressurised metered dose inhaler. Expert Opinion on Drug Delivery, pp. 215-234.

Bikiaris, 2011. Solid dispersions, Part I: recent evolutions and future opportunities in manufacturing methods for dissolution rate enhancement of poorly water-soluble drugs. Expert Opinion on Drug Delivery, pp. 1501-1519.

Bloxham, Eicher-Lorka, J. \& Niaura, 2002. The C-S bond in ethylthiols: a study of the characteristic Raman vibrational Spectral Band. Chemija, 13(4), pp. 190-193.

Brain, Kreyling \& Godleski, 2014. Inhalation Toxicology. In: Wallace \& Kruger, eds. Hayes'

Principles and Methods of Toxicology, Sixth Edition. Boca Raton, FL: CRC Press, pp. 1402-1414.

Broday \& Georgopoulos, 2001. Growth and Deposition of Hygroscopic Particulate Matter in the Human Lungs. Aerosol Science and Technology, p. 144-159.

Bur, Huwer, Muys \& Lehr, 2010. Drug Transport Across Pulmonary Epithelial Cell Monolayers: Effects of Particle Size, Apical Liquid Volume, and Deposition Technique. Journal of Aerosol Medicine and Pulmonary Drug Delivery, 3(23), pp. 119-127.

Calverley, et al., 2003. Combined salmeterol and fluticasone in the treatment of chronic obstructive pulmonary disease: a randomised controlled trial. The Lancet, pp. 449-456.

CCDC, 2015. WebCSD v1.1.1. [Online]

18 Available at: http://webcsd.cds.rsc.org/index.php

19 [Accessed 1011 2015].

Cejka, Kratochvil \& Jegorov, 2005. Crystal Structure of Fluticasone Propionate, C25H31F3O5S. Zeitschrift für Kristallographie - New Crystal Structures, pp. 143-144. combination Diskus inhaler: as effective as when given via separate Diskus inhalers.. Canadian Respiratory Journal: Journal of the Canadian Thoracic Society, pp. 45-51.

Clark, 1994. Medical Aerosol Inhalers: Past, Present, and Future. Aerosol Science \& Technology, pp. 374-391.

Clegg \& Brimblecombe, 1998. A thermodynamic model of the system H+ - NH4+ - Na+ - SO42- NO3- - Cl- - H2O at 298.15 K. The Journal of Physical Chemistry, 12(102), pp. 2155 - 2171.

Clegg, Seinfeld \& Brimblecombe, 2001. Thermodynamic modelling of aqueous aerosols containing electrolytes and dissolved organic compounds. Journal of Aerosol Science, Issue 32, pp. 713-738. Coates, 2000. Interpretation of Infrared Spectra, A Practical Approach. In: Encyclopedia of Analytical Chemistry. Chichester: John Wiley \& Sons Ltd, pp. 10815-10837. metered dose inhalers. Respiratory Medicine, 94(2), pp. S3-S9. metered-dose inhaler. Journal of Aerosol Medicine and Pulmonary Drug Delivery, pp. 85-97. 
1 Delgado, Chou, Silver \& Crain, 2003. Nebulizers vs metered-dose inhalers with spacers for bronchodilator therapy to treat wheezing in children aged 2 to 24 months in a pediatric emergency department.. Archives of Pediatric and Adolescent Medicine, pp. 76-80.

Dodson, et al., 2011. Photophysical and photochemical properties of the pharmaceutical compound salbutamol in aqueous solutions. Chemosphere, pp. 1513-1523.

Dolovich, Ruffin, Roberts \& Newhouse, 1981. Optimal delivery of aerosols from metered dose inhalers. Chest, 80(6), pp. 911-915.

Engelhart, et al., 2011. Water content of aged aerosol. Atmospheric Chemistry \& Physics, Issue 11,

9 pp. 911-920.

Eom, et al., 2014. Influence of collecting substrates on the characterization of hygroscopic properties of inorganic aerosol particles.. Analytical Chemistry, 4(86), pp. 2648-2656.

Ferron, 1977. The size of soluble aerosol particles as a function of the humidity of the air. Application

Feth, et al., 2008. USA, Patent No. US20100120737 A1.

Feth, et al., 2007. Physicochemical, Crystallographic, Thermal, and Spectroscopic Behavior of Crystalline and X-ray Amorphous Ciclesonide. Pharmaceutics, Preformulation and Drug Delivery, pp. 3765-3780.

Haddrell, et al., 2014. Dynamics of aerosol size during inhalation: Hygroscopic growth of commercial nebulizer formulations. International Journal of Pharmaceuticals, pp. 50-61.

Harding, 1990. The human pharmacology of fluticasone propionate. Respiratory Medicine, pp. 25-29.

Hardy \& Chadwick, 2000. Sustained Release Drug Delivery to the Lungs. Clinical Pharmacokinetics, pp. 1-4.

Hargreaves, et al., 2010. Measurements of the Equilibrium Size of Supersaturated Aqueous Sodium Chloride Droplets at Low Relative Humidity Using Aerosol Optical Tweezers and an Electrodynamic Balance. The Journal of Physical Chemistry, pp. 1806-1815.

Hirschfeld \& Chase, 1986. FT-Raman Spectroscopy: Development and Justification. Applied Spectroscopy, 08 January.pp. 133-137.

Huang, et al., 2003. Near-infrared Raman spectroscopy for optical diagnosis of lung cancer. International Journal of Cancer, pp. 1047-1052.

30 Hung, Chu, Wang \& Yang, 1999. Hypoalkaemia and salbutamol therapy in asthma. Pediatric 31 Pulmonology, pp. 27-31.

32 Hunt, Ward \& King, 2013. Laser heating of sulfuric acid droplets held in air by Raman tweezers. RSC 33 Advances, pp. 19448-19454.

34 Hunt, Ward \& King, 2015. Heterogeneous oxidation of nitrite anion by gas phase ozone in an aqueous 35 droplet levitated by laser tweezers (optical trap): is there any evidence for enhanced surface reaction?. Physical Chemistry Chemical Physics, pp. 2734-2741. 
1 Ibrahim, Verma \& Garcia-Contreras, 2015. Inhalation drug delivery devices: technology update.

2 Medical Devices (Auckland), Volume 8, pp. 131-139.

3 Icha, 2007. Ventolin remains a breath of fresh air for asthma sufferers, after 40 years. The

4 Pharmaceutical Journal, p. 404.

5 ICRP, 1994. Ann. ICRP 24 (1-3) publication 66: Human Respiratory Tract Model for Radiological

6 Protection, s.l.: Elsevier Health Sciences.

7 Janson, et al., 2016. Difference in resistance to humidity between commonly used dry powder

8 inhalers: an in vitro study. npj Primary Care Respiratory Medicine, Issue 23, p. 16053.

9 Jones, King \& Ward, 2015. Atmospherically relevant core-shell aerosol studied using optical trapping

10 and Mie scattering. Chemical Communications, pp. 4914-4917.

11 Kwon, et al., 1994. Vibrational Spectroscopic Investigation of Benzoic Acid Adsorbed on Silver.

12 Journal of Physical Chemistry, pp. 8481-8487.

13 Labiris \& Dolovich, 2003. Pulmonary drug delivery. Part I: Physiological factors affecting therapeutic 14 effectiveness of aerosolized medications. Journal of Clinical Pharmacology, p. 588-599.

15 Lavorini, et al., 2011. Retail sales of inhalation devices in European countries: So much for a global 16 policy. Respiratory Medicine, pp. 1099-1103.

17 Lawrence, 2005. The relationship between relative humidity and the dew point temperature in moist 18 air: A simple conversion and applications. Bulletin of the American Meterorological Society, pp. 22519233.

20 Leach, 2005. The CFC to HFA Transition and Its Impact on Pulmonary Drug Development.

21 Respiratory Care, 50(9), pp. 1201-1208.

22 Lee, et al., 2012. The Efficacy of Immediate Diet for Reducing Local Adverse Events of Inhaled

23 Corticosteroid: A Pilot Study. Tuberculosis and Respiratory Diseases, pp. 93-99.

Leger, Goursolle \& Gadret, 1978. Structure Cristalline du Sulfate de Salbutamol [tert-Butylamino-2 (Hydroxy-4 hydromethyl-3 phenyl)-1 Ethanol.1/2H2SO4]. Acta Crystallographica Section B, pp. $26 \quad 1203-1208$.

Lide, 1991. CRC Handbook of Chemistry and Physics. Boca Raton, FL: CRC Press.

Ling \& Chan, 2008. Partial crystallization and deliquescence of particles containing ammonium sulfate and dicarboxylic acids. Journal of Geophysical Research, 113(14), pp. 1-15.

30 Lipasek, et al., 2013. Effect of Temperature on the Deliquescence Properties of Food Ingredients and 31 Blends. Journal of Agricultural and Food Chemistry, pp. 9241-9250.

32 Lipworth \& Jackson, 2000. Safety of Inhaled \& Intranasal Corticosteroids Lessons for the New 33 Millennium. Drug Safety, 1(23), pp. 11-33.

34 Macrae, et al., 2006. Mercury: visualization and analysis of crystal structures. Journal of Applied 35 Crystallography, Volume 39, pp. 453-457.

36 Mansour, et al., 2016. 11.4 Particle deposition in the airways. In: Hillary \& Park, eds. Drug Delivery:

37 Fundamentals and Applications, Second Edition. Boca Raton, FL: CRC Press. 
Mutch, et al., 2007. The role of esterases in the metabolism of ciclesonide to desisobutyrylciclesonide in human tissue. Biochemical Pharmacology, pp. 1657-1664.

3 Nave, 2004. Saturated Vapor Pressure, Density for Water. [Online]

4 Available at: http://hyperphysics.phy-astr.gsu.edu/HBASE/Kinetic/watvap.html\#c1

$5 \quad$ [Accessed 6th August 2014].

6 Newman, N., 1996. Effect of add-on devices for aerosol drug delivery: Deposition studies and clinical

7 aspects. Journal of Aerosol Medicine: Deposition, clearance and effects in the lung, 9(1), pp. 55-70.

8 Newman, et al., 1981. Deposition of pressurised aerosols in the human respiratory tract. Thorax,

9 Volume 36, pp. 52-55.

10 Pandya, Berawala, Khatri \& Mehta, 2010. Spectrofluorimetric estimation of salbutamol sulphate in 11 different dosage forms by formation of inclusion complex with $\beta$-cyclodextrin. Pharmaceutical 12 Methods, pp. 49-53.

13 PerkinElmer Inc, 2008. Advantages of Raman Spectroscopy when Analysing Materials through Glass or Polymer Containers and in Aqueous Solution. [Online] Available at: http://www.perkinelmer.co.uk/CMSResources/Images/APP_RamanAnalysisTthrougGlassPolymerAq ueous.pdf

18 [Accessed 07 August 2014].

Phull, Rao \& Kankan, 2012. United States of America, Patent No. US 8158780 B2.

Purewal \& Grant, 1997. Metered Dose Inhaler Technology (Illustrated ed.). s.1.:Informa Health Care.

Reisine, Heisler, Hook \& Axelrod, 1983. Activation of beta 2-adrenergic receptors on mouse anterior pituitary tumor cells increases cyclic adenosine $3{ }^{\prime}: 5^{\prime}$-monophosphate synthesis and adrenocorticotropin release. The Journal of Neuroscience, pp. 725-732.

Renner, Mueller \& Shephard, 2012. Environmental and non-infectious factors in the aetiology of pharyngitis (sore throat). Inflammation Research, pp. 1041-1052.

Rkiouak, et al., 2014. Optical trapping and Raman spectroscopy of solid particles. Physical Chemistry Chemical Physics, pp. 11426-11434.

Rogueda, et al., 2011. Particle synergy and aerosol performance in non-aqueous liquid of two combinations metered dose inhalation formulations: An AFM and Raman investigation. Journal of Colloid and Interface Science, pp. 649-655.

Sanders, 2007. Inhalation therapy: an historical review. Primary Care Respiratory Journal, pp. 71-81. WILEY-VCH Verlag GmbH.

Stein, M., 2006. The Relative Influence of Atomization and Evaporation on Metered Dose Inhaler Drug Delivery Efficiency. Aerosol Science and Technology, Issue 40, pp. 335-347. 
Tetko, 2001. ALOGPS. [Online]

2 Available at: http://www.vcclab.org/lab/alogps/

$3 \quad$ [Accessed 2110 2016].

4 Theophilus, et al., 2006. Co-deposition of salmeterol and fluticasone propionate by a combination

5 inhaler. International Journal of Pharmaceuticals, pp. 14-22.

6 Tong, et al., 2014. Rapid interrogation of the physical and chemical characteristics of salbutamol

7 sulphate aerosol from a pressurised metered-dose inhaler (pMDI). Chemical Communications, pp.

$8 \quad 15499-15502$.

9 Tsuda, Henry \& Butler, 2013. Particle transport and deposition: basic physics of particle kinetics.

10 Comprehensive Physiology, Volume 4, pp. 1437-1471.

11 Ullman \& Svedmyr, 1988. Salmeterol, a new long acting inhaled beta 2 adrenoceptor agonist:

12 comparison with salbutamol in adult asthmatic patients. Thorax, pp. 674-678.

13 UNEP, 1987. The Montreal Protocol on substances that deplete the ozone layer., Nairobi: UNEP.

14 Vankeirsbilck, et al., 2002. Applications of Raman spectroscopy in pharmaceutical analysis. TrAC

15 Trends in Analytical Chemistry, pp. 869-877.

16 Walkowsky \& He, 2003. Handbook of aqueous solubility data. 1st ed. Boca Raton, Fl: CRC Press.

17 Wang, et al., 2014. Low-frequency shift dispersive Raman spectroscopy for the analysis of respirable

18 dosage forms. International Journal of Pharmaceutics, Issue 469, pp. 197-205.

19 Wittig, Lohmann \& Gmehling, 2003. Vapor-Liquid Equilibria by UNIFAC Group Contribution. 6.

20 Revision and Extension. Industrial \& Engineering Chemical Research, 42(1), pp. 183 - 188.

21 Woolcock, Lundback, Ringdal \& Jacques, 1996. Comparison of addition of salmeterol to inhaled

22 steroids with doubling of the dose of inhaled steroids.. American Journal of Respiratory and Critical

23 Care Medicine, pp. 1481-1488.

24 York \& Hanna, 1994. United States of America, Patent No. US5795594 A.

25 Zhejiang NetSun Co., Ltd., 2010. ChemNet.com - Global Chemical Network. [Online]

26 Available at: http://www.chemnet.com/cas/

27 [Accessed 2109 2015]. 